\title{
JOINING OF THICK METAL BY MULTIPASS ELECTROSLAG WELDING
}

\author{
K.A. YUSHCHENKO ${ }^{1}$, S.M. KOZULIN ${ }^{1}$, I.I. LYCHKO ${ }^{1}$ and M.G. KOZULIN ${ }^{2}$ \\ ${ }^{1}$ E.O. Paton Electric Welding Institute, NASU \\ 11 Bozhenko Str., 03680, Kiev, Ukraine. E-mail: office@paton.kiev.ua \\ ${ }^{2}$ Toliatti State University \\ 14 Belorusskaya Str., Toliatti, RF. E-mail: office@tetsu.ru
}

\begin{abstract}
Nonstandard schemes of ESW (multi-layer, well-like etc.) are mostly used for reconstruction repair of large-sized parts of heavy machine building. Through-thickness cracks are the most often type of fracture and they take place mainly in heavy-loaded machine parts being operated under alternating load. Such defects differ by large branching and twisting of the cracks as well as impressive sizes of fracture sections $(2.5-6.8) \cdot 10^{5} \mathrm{~mm}^{2}$. A method of muptipass consumable nozzle electroslag welding (MCNESW) is the most appropriate for performance of repair works. Science-based combination of developed technical and technological approaches in MCNESW realizing provides for weld metal with high ductility, homogeneous structure and hardness, absence of hardening structures in HAZ and defects in fusion zone. The method of repair of large through-thickness cracks in large-sized parts directly at operation site is successfully implemented at six enterprises. Technical scheme, workup level and versatile of technological process of MCNESW performance allows also recommending it for joining of thick metal during production of new welded metal structures. 16 Ref., 4 Figures.
\end{abstract}

Keywords: multipass electroslag welding, consum able nozzle, repair, large-sized parts, through-thickness cracks

Single-pass electroslag welding (ESW) is mostly carried out by three main means, i.e. wire electrodes, consumable nozzle and large-section electrodes. These means can be used for production of virtually all existing types of butt, fillet and tee-welded joints, obtaining at that longitudinal and circumferential welds as well as welds of complex profile [1]. Elements of the welded joints are classified on shape of weld longitudinal section according to GOST 15164-95 and DSTU 3490-96. Surfaces of edges being welded, forming an assembly gap, are produced by machining, flame and plasma cutting as well as after rolling. Efficiency of application of single-pass ESW in manufacture of new large-sized metal structures is provided by correct selection of welding equipment and complex solving of issues of technique and technology of weld performance.

Refining of structure of the welded joint metal and reduction of the level of residual stresses require application of a postweld expensive hightemperature treatment (HTT). Therefore, any decision on rejection or, at least, decrease of volumes of its application, is always a priority [2].

One of the ways of approaching of fullstrength joint to base metal without HTT is performance of ESW using the schemes differing from traditional ones, for example, by means of joining of thick metal with the help of multilayer welds [3-5]. Efficiency of ESW application in joining of bi-metal billets rises, if the joint is welded by two welds in sequence [6].

Nonstandard schemes of ESW are mostly used for reconstruction repair of the large-sized parts of heavy-machine building, including, directly at operation site. Work [7] generalizes accumulated scientific-production experience of organizing and performance of such works and technological recommendations, used by corresponding engineering services of many enterprises and organizations, are proposed.

Mineral resource industry, metallurgy, power engineering and other branches have a variety of different large-sized parts in the units, fractured during operation. This requires realizing of individual approach in organizing of repair work for each specific case. It can be caused, first of all, by geometry parameters and spatial position of a fracture place as well as technical supply of working place and conditions of repair.

This work is dedicated to generalization of the results of testing, development and implementation of effective techniques of ESW repair of the through-thickness cracks, appearing mainly in heavy-loaded machine parts. The typical example of such objects are the solid rectangular and profiled cross-section bearing bands of rotary kilns, 
which often fracture in operation due to throughthickness cracks [8]. Most of the bands, crosssection sizes of which make $(355-500) \times(900-$ 1350) $\mathrm{mm}$, are manufactured from medium-carbon steels of 35L type using traditional casting in sand molds or electroslag casting (steel 34LESh). Peculiarity of repair of such defects is related to significant extent with large branching and twisting of the cracks as well as impressive size of fracture sections (Figure 1), area of which can make (2.5-6.8) $10^{5} \mathrm{~mm}^{2}$. At that, the wide gaps, 2-5 times exciding standard ones, are inevitably formed after welding edge preparation and volume of the removed defective metal can make $0.3-0.4 \mathrm{~m}^{3}$. Rough oxidized surface of the edges (after removal of damaged metal by oxygen cutting) creates new difficulties for providing of quality fusion during ESW.

Methods of repair of through-thickness cracks in the bands at operation site using electric-arc methods of welding differ by extremely low efficiency and do not always provide the quality welded joints as well as required occupational hygiene conditions [8]. Application of ESW traditional methods is also ineffective due to large expenditure of time for delivery of large-sized welding equipment, complexity of assembly and operation of multielectrode machines at great height (more than $20 \mathrm{~m}$ ), and impossibility to receive guaranteed fusion of base metal edges with the weld in the beginning of welding, etc.

Application of some untraditional ESW methods [8-10] is complicated, mainly, due to impossibility of complete removal of the defect, having branching (spatial) character, providing of guaranteed fusion of edges being welded and low hot crack formation resistance of the welds.

Development of repair method to the maximum free of indicated disadvantages was necessary for solving of the issues of organizing of

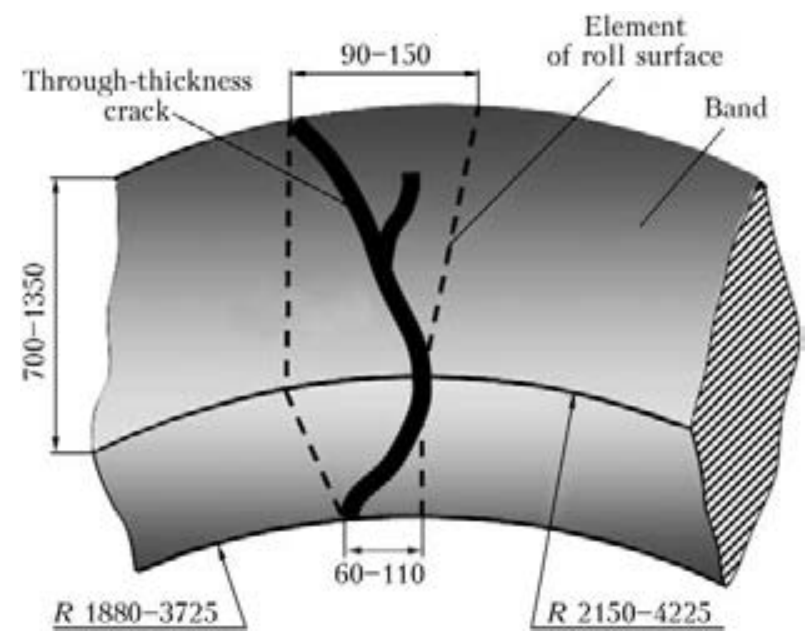

Figure 1. Scheme of typical positioning of crack in fractured band of rotary kiln

on-line repair of equipment with the throughthickness fractures at operation site.

In the best way these requirements are fulfilled by the method of muptipass consumable nozzle electroslag welding (MCNESW) (Figure 2) [11].

Metallurgical, energy and technical issues, related with specifics of reconstruction works, were investigated for development of MCNESW principle technology.

The following was determined as the results:

- mechanisms of defect-free formation of welded joint in a wide gap;

- conditions of guaranteed fusion and quality formation of weld;

- energy peculiarities of process from point of view of its stability and absence of defects in welded joints;

- conditions for prevention hot cracks in welds;

- effect of process thermal cycle on structure and mechanical properties of welded joint metal.
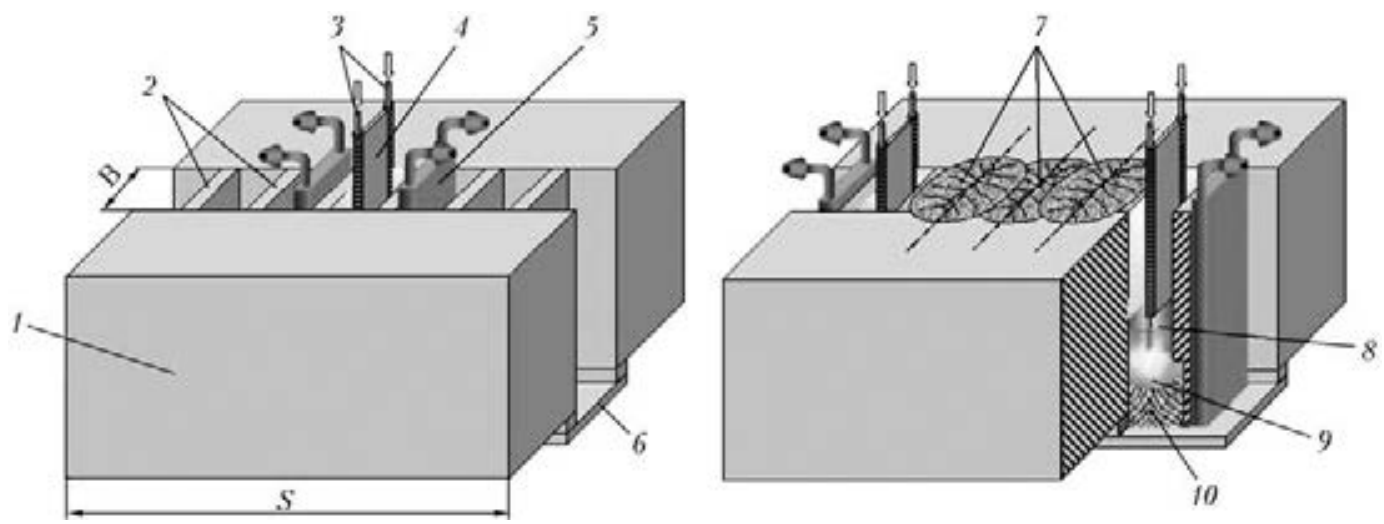

Figure 2. Scheme of the method of multipass ESW of big parts with large cross-section of elements being joined: 1 part being welded; 2 - forming inserts; 3 - electrode wire; 4 - consumable nozzle; 5 - water-cooled device; 6 hopper; 7 - welds; 8 - slag pool; 9 - metal pool; 10 - deposited metal; $S$ - thickness of metal being welded; $B-$ welding gap 

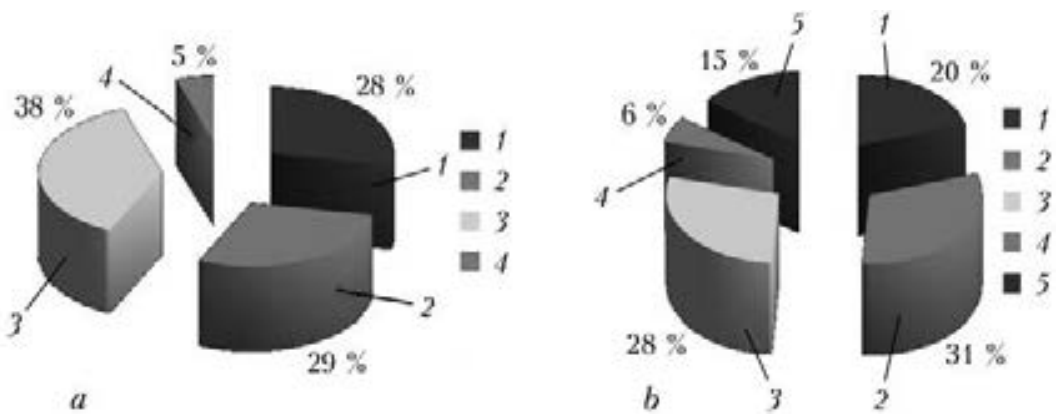

Figure 3. Portion of insert metal in composition of weld metal in MCNESW of the first (central) pass $(a)$ and adjacent passes $(b): 1$ - base metal; 2 - electrode wires; 3 - metal of inserts; 4 - plate of consumable nozzle; 5 - metal of adjacent weld

Required depth of base metal penetration and width of melting of forming insert for real gaps of $60-150 \mathrm{~mm}$, formed in area of occurrence of the through-thickness crack after removal of defective metal, are provided at values of welding process specific energy in the range of 220$340 \mathrm{~kJ} / \mathrm{cm}^{2}$.

Technological strength of welded joint metal is provided by set of measures, preventing hot crack formation [12, 13, 14], namely:

- reduction of weld metal shrinkage due to performance of multisection permanent joint by separate welds;

- positioning of weld plane in direction being in close agreement with tensile stress vector;

- reduction of level of tensile stresses in the period of solidification of metal pool due to flexibility of assembly separating inserts;

- selection of parameters of welding mode for each pass with weld shape coefficient in 5-8 range;

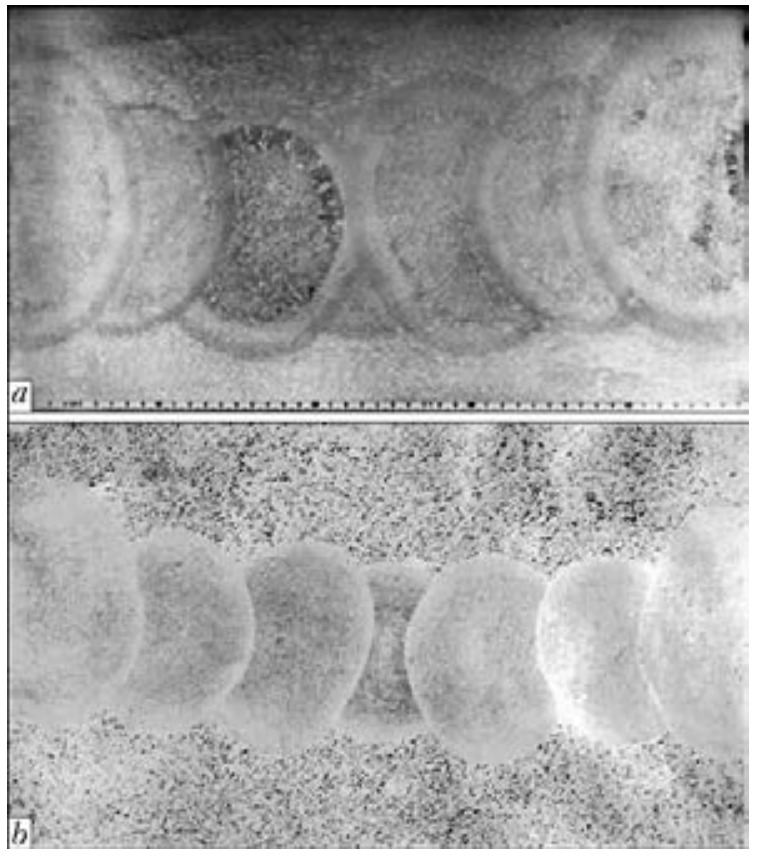

Figure 4. Transverse macrosection $(a)$ and sulphur print (b) of $480 \mathrm{~mm}$ thick welded joint produced by new MCNESW method
- distribution of stress field density by means of symmetric welding-up of separate sections of the assembly.

This process is characterized by such a type of welding thermal cycle, at which cooling rates of $\mathrm{HAZ}$ metal are very low $\left(0.2-0.8^{\circ} \mathrm{C} / \mathrm{s}\right)$, and time of staying of cooling metal in the range of the lowest stability of austenite is so long that conditions for HAZ structure formation can be considered closed to equilibrium [15].

Combination of welding wires of general designation with increased manganese content (for example, Sv-08G2 and Sv-10G2) and fused fluxes of $\mathrm{SiO}_{2}-\mathrm{MnO}-\mathrm{CaF}_{2}$ system (AN-8M and $\mathrm{AN}-9 \mathrm{U}$ ) during MCNESW of cast carbon steels of 35L type provides for required mechanical properties under conditions that material of assembly forming inserts will contain not less than $1 \% \mathrm{Mn}$ at low content of carbon and make 28-38 wt.\% from the deposited weld metal (Figure 3 ).

Sufficient strength of reconstructed metal of the welded joints in heavily-loaded assemblies of the structures from medium-carbon cast steels of 35L type under conditions of static and impact loading as well as high long-term strength at alternating load are provided [15] due to high ductility of weld metal, homogeniety of its structure and hardness, absence of hardening structures in HAZ and defects in the fusion zone ( $\mathrm{Fi}^{-}$ gure 4).

Technology for repair of the parts of unique equipment without its disassembly and specialized welding equipment [16] were currently developed using new MCNESW method. The technology was realized in repair of the throughthickness cracks of bands of rotary kilns at six enterprises. Experience of many years of operation of the reconstructed bands showed that longterm strength of the welded joints, produced by MCNESW under conditions of alternating loads, makes not less than $10^{7}$ cycles. Application of the developed technology in repair of the through-thickness cracks in bands of rotary kilns allowed 3 times reduction of the total time of 
repair works in comparison with repair using automatic submerged twin-arc welding.

\section{Conclusions}

1. MCNESW is the efficient method of repair of the through-thickness coarse cracks in large-sized parts, immediately at operation site, that is indicated by results of its successful implementation at six enterprises.

2. Science-based combination of the developed technologies and techniques during realizing of MCNESW provides for high ductility of weld metal, homogeneity of its structure and hardness, absence of hardening structures in HAZ and defects in fusion zone.

3. Versatile of technological process and procedure of MCNESW allows also recommending it for joining of thick metal in production of new welded metal structures.

1. (1980) Electroslag welding and surfacing. Ed. by B.E. Paton. Moscow: Mashinostroenie.

2. Paton, B.E. (1971) Some predictions on welding development. Avtomatich. Svarka, $\mathbf{5}$.

3. (1959) Electroslag welding. Ed. by B.E. Paton. Moscow; Kiev.

4. Anders, W., Maushake, W. Verfahren zum Verschweissen von Groessen Querschnitten mittels Elektroschlackeschweissung. Veroeff. 06.10.61.

5. Khoruzhik, G.I., Sushchuk-Slyusarenko, I.I., Andrianov, G.G. et al. Forming device for vertical weld- ing. USSR author's cert. 284224. Int. Cl. B $23 \mathrm{~K}$ $25 / 00$. Fil. 22.01.78. Regist. 21.03.80.

6. Sushchuk-Slyusarenko, I.I., Lychko, I.I., Khrundzhe, V.M. et al. Forming device for vertical welding. USSR author's cert. 747659. Regist. 23.01.78.

7. Sushchuk-Slyusarenko, I.I., Lychko, I.I., Kozulin, M.G. et al. (1989) Electroslag welding and surfacing in repair works. Kiev: Naukova Dumka.

8. Kozulin, S.M., Lychko, I.I., Kozulin, M.G. (2007) Methods of reconditioning rotary kilns (Review). The Paton Welding J., 10, 33-39.

9. Sushchuk-Slyusarenko, I.I. (1977) Electroslag welding and surfacing. Vol. 9. Moskow: Svarka.

10. Filchenkov, D.I., Kozulin, M.G., Sushchuk-Slyusarenko, I.I. (1982) Repair of defects of cast products from 30GSL steel by multilayer electroslag welding. Svarochn. Proizvodstvo, 9, 19-20.

11. Kozulin, M.G., Kozulin, S.M. (1992) Method of multilayer electroslag welding. USSR author's cert. 1756074. Int. Cl. B23K $25 / 00$. 33/00.

12. Kozulin, S.M. (2011) Selection of the groove shape for repair of through cracks by multilayer electroslag welding. The Paton Welding J., 3, 32-35.

13. Kozulin, S.M., Lychko, I.I., Kozulin, M.G. (2010) Increase of resistance of welds to formation of crystalline cracks in repair of bands of kiln furnaces using electroslag welding. Ibid., 1, 32-34.

14. Kozulin, S.M., Lychko, I.I. (2011) Deformations of welded joints in multilayer electroslag welding. Ibid., 1, 23-27.

15. Kozulin, S.M., Lychko, I.I., Podyma, G.S. (2013) Structure and properties of steel 35L welded joints produced using multilayer electroslag welding. Ibid., 8, 7-12.

16. Yushchenko, K.A., Lychko, I.I., Kozulin, S.M. et al. (2012) Portable apparatus for consumable-nozzle electroslag welding. Ibid., 8, 45-46.

Received 14.07.2014 